1968

\title{
The Social Institution of Insanity
}

Frank A. Chesno

College of William \& Mary - Arts \& Sciences

Follow this and additional works at: https://scholarworks.wm.edu/etd

Part of the Psychiatric and Mental Health Commons

\section{Recommended Citation}

Chesno, Frank A., "The Social Institution of Insanity" (1968). Dissertations, Theses, and Masters Projects. Paper 1539624661.

https://dx.doi.org/doi:10.21220/s2-sh9q-b787

This Thesis is brought to you for free and open access by the Theses, Dissertations, \& Master Projects at W\&M ScholarWorks. It has been accepted for inclusion in Dissertations, Theses, and Masters Projects by an authorized administrator of W\&M ScholarWorks. For more information, please contact scholarworks@wm.edu. 
THE SOCIAL INSTITUTION OF INSANITY

\author{
A Thesis \\ Presented to
}

The Faculty of the Department of Psychology

The College of William and Mary in Virginia

In Partial Fulfillment

Of the Requirements for the Degree of

Master of Arts

By

Frank A. Chesno

1968 
APPROVAL SHEET

This thesis is submitted in partial fulfillment of the requirements for the degree of Master of Arts

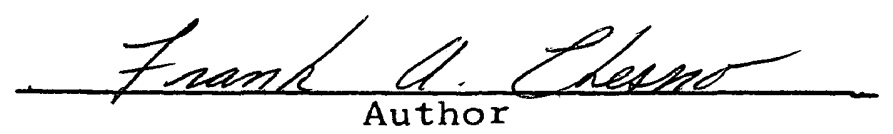

Approved, May 1968

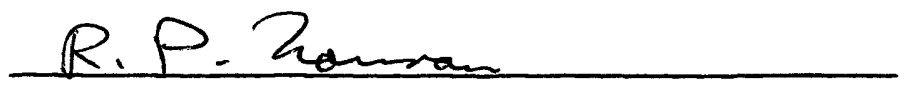

R. Philip Norman, Ph.D.

$\frac{\text { Vigil K. YheKeura }}{\text { virgie v. Mckenna, Ph.D. }}$

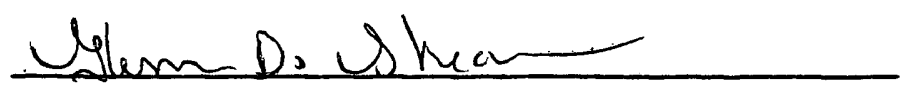

Glenn D. Shear, Ph. D.

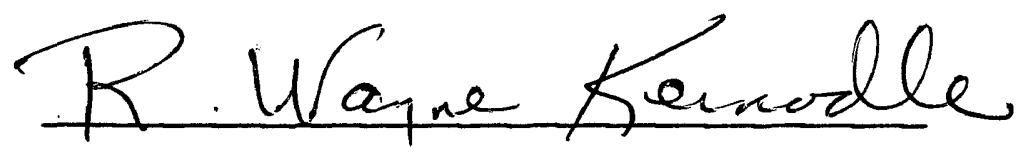

R. Wayne Kernodle, Ph. D.

Stambul B.Werains

Stanley B.VWiliams, Ph.D.

Chairman

Department of Psychology

ii 


\section{ACKNOWLEDGMENTS}

The writer wishes to express his appreciation to Dr. R. Philip Norman, under whose guidance this investigation was conducted, for his patient guidance and criticism throughout the investigation. The author is also indebted to Dr. Virgil V. McKenna and Dr. Glenn D. Shean for their careful reading of the manuscript. 
ACKNOWLEDGMENTS .........................

LIST OF TABLES............................ v

ABSTRACT $\ldots \ldots \ldots \ldots \ldots \ldots \ldots \ldots \ldots \ldots \ldots \ldots \ldots \ldots \ldots \ldots \ldots$

INTRODUCTION.............................. 2

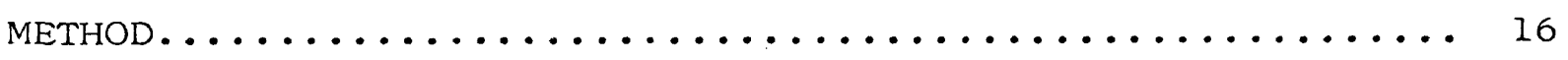

RESULTS................................ 24

DISCUSSION...................................... 39

APPENDTX............................... 50

BIBLIOGRAPHY............................. 56 


\section{LIST OF TABLES}

Table

Page

1. Group Instructions and Training.............. 18

2. Analysis of Variance for Age Differences......... 25

3. Analysis of Variance for Educational Differences.... 26

4. Analysis of Variance of Initial Es Scores......... 28

5. Mean Es and CI Endorsements................ 30

6. Analysis of Variance of Initial CI scores......... 3I

7. Mean Changes Between Initial and Final Es and

Cr Endorsements................... 34

8. $x^{2}$ Test for Differences in Release Rate among

the Three Groups.................. 38 


\section{ABSTRACT}

The purpose of this study is to investigate some of the effects of societal reaction and the labeling process upon the deviate perceived as mentaliy ill.

An experimental situation was devised in which mental patients were tested at the beginning of hospitalization and after a 30 day observation period on their ability to role-play normalcy. One group of patients received daily training in role-playing normalcy.

Patients released from the hospital at the end of the observation period showed more improvement in their ability to role-play normalcy than those detained for continued hospitalization. Patients who received training in role-playing normalcy were released from the hospital more often than those who were not trained.

It is suggested that patients who are able to avoid playing the role of mentally ill and are able to maintain their familiarity with normal roles are more likely to resist societal pressures which may have the effect of encouraging committment to the deviant role. 
THE SOCIAL INSTITUTION OF INSANITY 


\section{$\underline{\text { INTRODUCTION }}$}

Research concerned with the etiology of mental illness has largely been based upon models which emphasize the importance of individual or internal factors in the development and maintenance of mental disorder. Organic theories have been employed in investigations of genetic phenomena as possible causes of mental illness (i.e., Kallman, 1964; Book, 1953). Closely related to the genetic models have been the biochemical approaches which relate metabolism and types of behavioral pathology, particularly schizophrenia (Heath, 1960). Other applications of organic theory have been made in investigations of the relationship between physiology and behavior pathology (i.e., Crammer, 1957).

Functional theories have been more widely utilized than organic theories in building models to investigate the causes of mental disorder. They, too, have postulated disturbances in the inner mechanisms of the disturbed individual. Angyal (1946), Goldstein (1943), and Bleuler (1950) for example, suggested that disturbances in cognitive functioning are major determinants of mental illness. Klein (1951), Stevens (1951), and Witkin (1954) indicated that behavioral pathology may be rooted in impaired perceptual functioning. Freud (1924) and countless psychoanalytic followers have offered explanations based upon affective disorders. Many of these theorists have relied on social conditions external to the individual for explanations of the origins of disturbances. 
Furthermore, these theorists have generally attributed considerable importance to environmental factors which interact with the individual. None the less, they have preferred to view the actual disorder as residing within the sick individual. Even theorists who have used social - psychological models of mental illness (i.e., Adler, 1927; Sullivan, 1953) have looked more toward the sick person than society for an explanation of his social breakdown. Emphasis upon the individual has led to a neglect of the importance of the social context in which he operates.

Unlike the organic and functional models which have focused their attention upon the sick individual himself, a more recent, behavioristic approach to maladjustment (Wolpe, 1958; Eysenck, 1959) has helped to place increased emphasis upon factors outside the individual. By manipulating environment with the aid of traditional learning principles, behavior therapy techniques have been used to control neurotic and psychotic symptoms (Lazarus, 1963; Wolpe, 1961; Ayllon, 1963). Central to behavior therapy is the doctrine that mental disorders not only express themselves through symptoms, but actually are no more than the sum total of the symptoms. By reducing mental disorder to symptomology and demonstrating external control of symptoms, behavior therapists have placed some of the causes of mental illness outside of the individual.

Recent sociological studies by Hollingshead and Redich 
(1958) and Myers and Roberts (1959) have pointed out the significance of social factors in the development, expression, and types of mental illness. Members of lower socio-economic classes, for example, are more likely to express schizophrenic symptoms, while those in higher classes generally manifest neurotic and manic - depressive reactions. Findings such as these help specify the relationship between external social variables and mental disorder. Social class variables may be essential, then, in a representative model of mental illness.

Even a brief review of the literature of systematic approaches to the study of mental illness indicates the scope and complexity of the topic. Understanding the phenomena involved will undoubtedly require a multivariate approach from many levels of investigation. This study represents an attempt to examine some of the external social factors involved in mental illness. It is not concerned with the more traditional individual models based upon organic and functional theories, except where they contribute to an understanding of the social factors involved. More specifically, the framework is closely aligned with Scheff's (1966) sociological theory of mental illness which is based upon a conceptual model concerned with the social system rather than the individual. Other concepts are added to contribute further justification for the hypotheses tested. The approach taken is not intended to represent a comprehensive account of mental disorder. It is meant, rather, as an investigation of some of the external, 
social factors which may be operating when a person ceases acting as a normal individual and comes to be viewed as a mental patient.

Paramount to Scheff's model are the concepts of normalcy and deviance. The definition of deviance has long been of concern to sociologists and it has been conceptualized from many points of view. The statistical approach defines deviance as a wide discrepancy from the mean. Such an approach provides only a relative insight into deviance. It describes deviance only on the basis of that from which it deviates, in place of investigating the phenomenon itself. An alternative approach to defining deviance is based upon a medical explanation. Deviance is seen as a disease, as something qualitatively different from its normal counterpart. Durkheim's concept of anomie serves as a classic example of formulating deviance in terms of a medical or pathological model. Another view related to the medical model sees deviance represented by those aspects of society which are stressful or dangerous to the well-ordered functioning of the social system. Deviance, then, is considered as the dysfunctional aspects of society (Merton, 1961).

The most traditional sociological interpretation has viewed deviance as the failure to obey group norms. This definition allows for various interpretations of deviance by different groups or cultures. Tannenbaum (1951), Lemert (1951), Kitsuse (1962), and Becker (1963) have added to this last definition 
the concept that deviance is produced by society -- not by the individual. This important qualification shifts the focus of attention from the deviate to the social systems which "create deviance by making the rules whose infraction constitutes deviance, and by applying those rules to particular people and labeling them as outsiders" (Becker, 1963). By this definition deviance is relative not only to the norms which society makes, but also to the reaction it makes toward the rule breaker. The deviate, then is not just the person who violates norms, but the violator who has been labeled as deviant. If the labeling process does not occur, the rule breaker is not a deviate. On the other hand, if the labeling process does occur, its victim may be forced into a deviant role even though he may not have broken the rules of which he was accused. This is the concept of deviance which Scheff has employed in his model of mental illness.

Another sociological concept central to Scheff's theory and important to this investigation of the social factors relevant to mental illness is that of role-playing. Societies are complex machines marked by intricate interaction between component parts. Despite an apparent unity of purpose, society is composed of many heterogeneous factors. Individuals within the society function in relatively well-planned fashion. Their contributions to the total effort may be conceptualized as the enactment of various roles. Voluntarily or involuntarily, consciously or 
unconsciously, each individual is constantly at work meeting the demands of the roles to which he has been assigned." Strong sanctions are maintained to discourage individuals from abandoning the directives of their roles.

Roles may be ascribed or achieved. They are differentially defined according to the society in question. Roles are affected by hereditary and environmental influences. They determine, to a large extent, the individual's self-image (Sargent and Williamson, 1966). Moreno (1962) described the psychoanalytic concept of self as nothing more than the result of the roles an individual plays, viz., "Roles do not emerge from the self, but the self emerges from roles." Role is a concept which is social in nature since it demands at least two persons, each of whom has a set of expectations concerning the other (Newcomb, 1965). Sargent (1951) has defined role as "...a pattern or type of social behavior which seems situationally appropriate to ...(an individual)... in terms of the demands and expectations of those in his group". Various disciplines have made use of the role concept in attempting to explain or manipulate behavior. Davidson (1961) reported on a role-playing situation designed to teach political concepts to college students. Mann(1959) attempted to induce changes in personality and behavior characteristics through role-playing techniques. Leveen and Priver (1963) suggested a theory based upon role-playing to explain degeneration in aged persons. Willens (1965) found that training in interpersonal 
skills induces more appropriate and more involved interaction among schizophrenics. These and many other reports in the literature indicate the wide-spread acceptance and application of role theory. The role concept generally ignores the individual's cognitive, perceptual, and affective mechanisms, but reveals the importance of external social factors in adjustment and pathology. In an effort to formulate a testable social model of mental illness, Scheff drew heavily upon sociological theories of deviance and role-playing. He made the initial assumption that, in most social systems, there is abundant rule breaking arising from many sources. Some rule breaking is noticed and acted upon. Murderers are jailed, traffic violators are fined, irresponsible parents are brought to the attention of welfare authorities. There remains, however, considerable additional rule breaking which does not come to society's attention, which is "denied", or which has no formalized sanctions assigned to it. Since violators of the last type of rules are not as clearly recognizable as more formal violators, they are not generally dealt with as deviates and may continue temporarily or permanently unhampered by society. If, however, the rule breaking becomes particularly noticeable, a labeling process might result.

Szasz (1961) has argued that labeling a person as mentally ill is immediately effective in reducing the confusion and shame generated by his overt rule breaking. As the label of 
mental illness is being applied, societal reaction generates and proffers a new set of roles to the deviate. Scheff asserted that the stereotype of insanity is itself a well-defined, wellspecified role. It is familiar to all directly and vicariously through jokes, anecdotes, conventional phrases, and biased reporting in daily conversation and the mass media.

The newly-labeled rule breaker is quickly stripped of former rights, roles, and obligations. By accepting the role implied by mental illness, he can escape the temporary state of personal anomie created by societal reaction. Society attempts to perpetuate the labeling process by isolating the deviate in a mental hospital and by throwing up a wall of resistence against his efforts to return to normal or prehospital roles. Instances of this resistence can be seen in society's reluctance to allow the deviate to return to the community, to be reemployed, or to take on former responsibilities.

Once hospitalization has occurred, further resocialization processes confirm the deviate in the mentally ill role. Goffman (1961) has pointed out the effectiveness of institutionalization in removing all past supports from the deviate and adapting him to the institution's designs. The processes operating are powerful ones because, at the time of public labeling, the deviate is in a highly suggestible state (Scheff, 1966). His qualifications to return to previous roles will be judged on a model which presupposes internal or medical pathology when, in 
fact, his plight may be largely or completely due to social forces operating beyond his sphere of responsibility and control. In effect, the deviate may be a victim of the ignorance and injustice of his society.

The present study concerned itself with the period immediately subsequent to public labeling and hospitalization - - the beginning of a "deviant career" (Becker, 1963). The hypotheses tested relied not only upon Scheff's assumptions, but also drew from several major psychological theories. The latter were interpreted as being helpful in justifying some of Scheff's assumptions and useful for predicting the types of changes that labeling and hospitalization may produce.

An application of Festinger's (1957) principles of cognitive dissonance was seen as useful in investigating the situation of the new Iy-labeled deviate. The processes of labeling and institutionalization combine to radically alter the deviate's former roles and self-image. His place and function in the social system have likewise undergone profound changes. Previous correct concepts of normal and expected behavior cannot always be applied with success in his current situation. The deviate may experience considerable dissonance between the present and the past. Due to the powerful resistence blocking his return to prehospital roles, the stress and embarrassment recently experienced in outside society, and the possible advantages afforded by hospitalization, the deviate may choose to reduce 
his dissonance by closely identifying with his new status. By accepting the deviant role, he may simultaneously diminish the subjective importance of previous roles. Many of the studies in the dissonance literature utilize role-playing situations as a source of dissonance generation and reduction. While varied results and artifacts have brought dissonance theory into question, it is generally held that, under certain circumstances, dissonance can effect substantial changes in opinions, attitudes, and selfconcepts (Clarke, 1965).

Evaluating the situation presented the recently hospitalized deviate in relation to learning principles may be useful for making predictions concerning his committment to the deviant role. From the beginning of hospitalization, many of the stimulus patterns impinging upon the deviate are generated by those who have accepted roles of mental illness. Extinction of responses learned in normal environments remove him still further from the normal aspects of his prehospital roles. Scheff (1966) found that it is positively reinforcing to the patient to admit to symptoms and problems. Hospital personnel may interpret the lack of such an admission as resistence and lack of insight. Reward and punishment, therefore, may be administered in a fashion that encourages committment to the deviant role. Mahrer (1963) using a symptom check list found that patients admit to more psychiatric symptoms after two months of hospitalization than upon admission. On the basis of learning principles, Cohen 
(1965) postulated that "the deviate finds, builds, tests, and validates a new self". Swartz, Fearn, and Stryker (1966) found that deviant children discover a coherent stable identity in the role of disturbed child. Bandura (1963) has established the importance of models as determinants of behavior. The likelihood of patients observing and being influenced by normal models is considerably reduced in the hospital setting. Models may often be other more committed deviates.

$$
\text { Asch's (1956) formulations concerning conformity may be }
$$
useful in understanding and predicting the patient's assimilation of the deviant role. Perception and judgment are partly a function of the immediate group in which one finds himself. The mental patient, particularly in a state hospital, mingles with a considerable number of other deviates. His attitudes, values, and self-image may be modified in the direction of the deviate image. The fact that some patients fail to assimilate the deviant role and leave the hospital relatively quickly may also be compatible with conformity theory. Asch described some persons as "independent" rather than "yielding" when rating them upon their sensitivity to being affected by those in their immediate surroundings. Perhaps the "independent" is more successful than the "yielder" in resisting the deviant role.

Normal and deviant roles have been consistenly distinguished by social systems as well as by investigators of social phenomena. The it iterature provides numerous examples of the differences 
between normal and deviant behavior. Rogers (1951) used data from clinical cases to support his contention that the disparity among self, ideal, and other concepts is far greater among psychotics (deviates) than among normals. While the self and ideal concepts of paranoid schizophrenics are generally relatively congruent, they are unrealistically lofty (Friedman, 1955; Hillson, 1957; Rogers, 1958). Another way of demonstrating normal and deviate differences has been the comparison of social comprehension among normals and schizophrenics. Senf, Hutson, and Cohen (1956) demonstrated that schizophrenics display considerable confusion in attempting to interpret normal roles such as those of mother, father, etc. Chambers (1957) related the severity of mental illness to the degree of misinterpretation of traits exhibited by human photographs.

Further evidence of the differences between normal and deviant role-players was observed by Stanton and Schwartz (1954). Attitudes revealed among mental patients indicated that they expect model adjustment on the part of staff members. On the other hand, patients felt that their behavior should not be condemned if irresponsible or unhealthy. According to this observation, the deviate perceives himself as subject to a very different morality and ethic than that imposed upon normals.

Grayson and Olinger (1957) have reported on a role-playing situation in a clinical setting. Mental hospital patients were instructed to answer MMPI questions "in the way a typical, well- 
adjusted person would". The resulting profiles were compared with the responses given by the same patients on a previous MMPI administered with standard instructions. Comparison showed that, despite the degree or type of pathology indicated by the initial test, clinical improvement and hospital discharge were related only to the amount of improvement shown on the simulated profile. Sarbin (1964) and Hass and Cabin (1966) have verified these findings with similar role-playing designs. Interpreting these results in light of Scheff's theory suggests that patients who seem to resist social pressures and remain proficient in the ability to play normal roles may be able to avoid the effects of the labeling process.

The present study attempted to investigate and measure the changes caused by the labeling process in the early stages of hospitalization. It was assumed that the newly labeled deviate's early experiences in the mental hospital would be significant in determining the extent of his ultimate committment to the deviant role. An attempt was made to intervene in the labeling process by training one group of patients to role-play normalcy. The following hypotheses were tested:

1. Mental patients will be able to role-play normalcy more effectively upon admission than after a period of hospitalization. This prediction is based upon role-playing, dissonance, learning, and conformity factors which may have the effect of confirming mental 
patients in the deviant role which society has ascribed to them.

2. Patients released from the hospital will be tho se who improve their ability to play the normal role. By showing proficiency in stimulating normalcy, they will be successful in resisting the deviant label.

3. Patients who receive daily training in role-playing normalcy will improve their ability to simulate normalcy. As a result, more trained patients will be released from the hospital than non-trained patients. This prediction is based upon the assumption that intervention in the labeling process will enable patients to resist deviant status. 


\section{Method}

$\underline{\text { Subjects }}$

Subjects (SS) were patients at Eastern State Hospital. Negro patients were not included because of the present-day confusion regarding normal and deviant behavior in the Negro community. Ss were restricted to an age range of 16 to 60 . Illiteracy was a disqualifying factor. Seven Ss were eliminated from the study because they were found to be in a very confused or depressed. state or because cooperation could not be elicited. Two $\underline{\text { Ss }}$ were not used because they failed to follow instructions properly. A total of 52 Ss participated in the study. Ss were assigned to one of three groups, matched for age, education, and number of admissions to psychiatric hospitals. One group served a semi-control, semi-experimental function, another was used as a treatment group, and the last served a control function. The groups were composed of 18, 17, and 17 Ss respectively.

\section{Questionaire}

A questionaire was used which was composed of two scales made up of items taken from the Minnesota Multiphasic Personality Inventory (MMPI). One scale, the Ego strength scale (Barron, 1953) was employed as a measure of health and adjustment. Barron found that the Ego Strength (Es) scale correlates highly with a 
favorable prognosis. Patients with higher scores - those who endorse more items correctly - are more likely to be successful in psychotheraputic situations. Normals endorse Es items at a higher rate than psychiatric patients. The second scale, the Critical Items (CI) scale, developed by Grayson (1951), is generally used as a device to screen psychiatric patients for those presenting very severe symptoms. The scale is composed of items whose endorsement indicates gross pathology. In most cases, valid endorsement suggests psychotic symtomology. The CI scale was intended here as a measure of illness and deviance as opposed to the Es measure of health and adjustment. The Es and CI items were arranged in the same order as they appear in the MMPI. Items common to both scales were used only once; the total number of items was 100.

$\underline{\text { Procedure }}$

Each $\underline{S}$ was approached on the day following his admission to the hospital and asked to accompany the Experimenter (E) to a testing room. E introduced himself and informed the patient that he was interested in getting to know him better. E further explained that this could best be accomplished by the patient's completing a questionaire. E presented $\underline{S}$ with the test material and gave him the appropriate instructions.

Table $I$ indicates the type of instructions each group received. Ss assigned to the control group were asked to complete the questionaire so as to express their true feelings regarding 


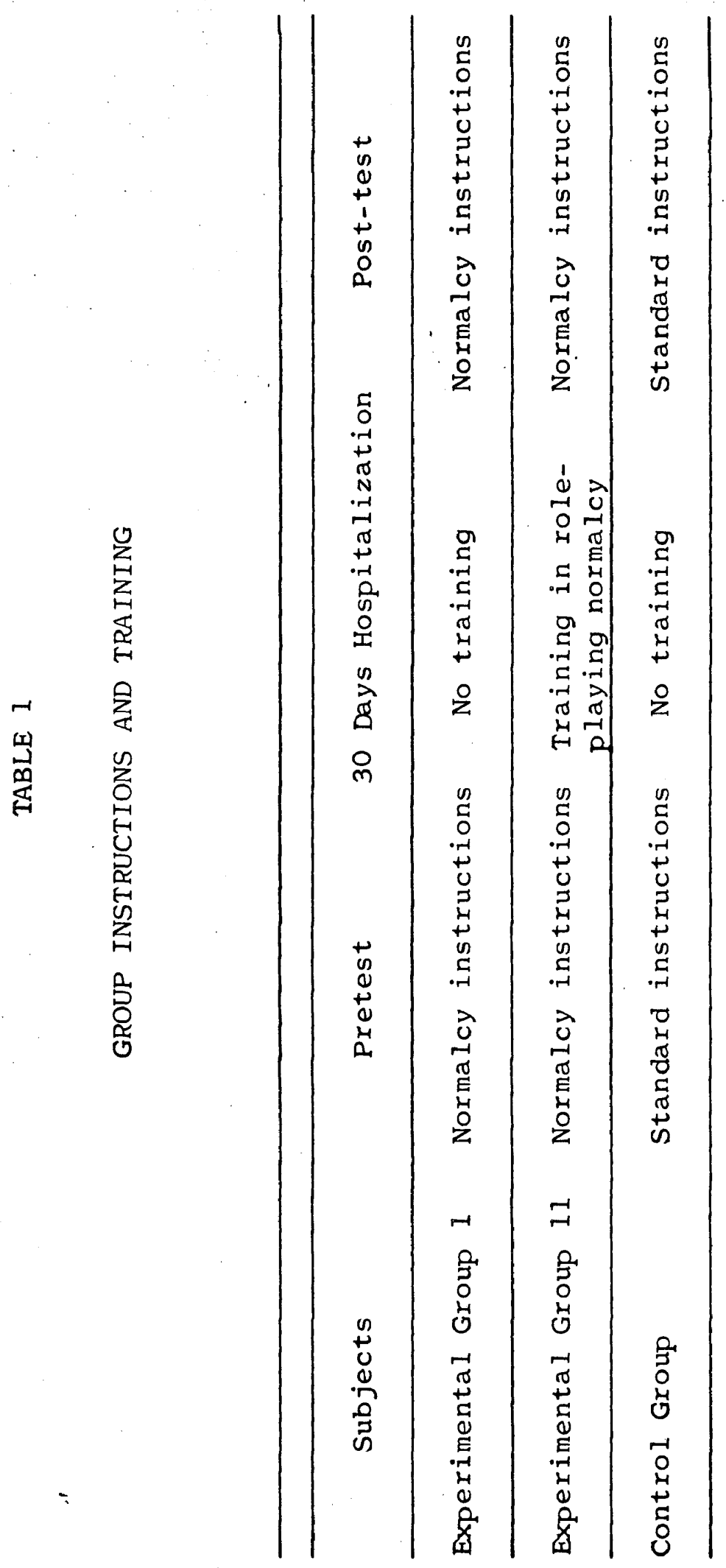


each question (standard instructions). Ss assigned to the other two groups were asked to answer the questions in the manner they would expect from "a well-adjusted, normal person". The latter instructions (normalcy instructions) were designed to encourage. Ss to role-play normalcy. All Ss were questioned regarding the instructions both before and after they had completed the questionaire. If they could not repeat the original instructions in an acceptable manner both times, they were dismissed fxom the study. Two Ss were lost on this account.

Patients admitted to Eastern State Hospital are kept on an observation ward for their first 30 days. At the end of this period, they are evaluated and diagnosed by the staff. Patients selected for this study were retested with the same questionaire, described above, on the day their cases were scheduked for staff conference. Again, depending upon the group to which they had been assigned, they were instructed to complete the questionaire to express their true feelings or to simulate the responses of a normal person.

Ss who made up the Control Group and those who were assigned to Experimental Group I received no treatment from the day of admission to the day of staff conference, beyond that of traditional hospitalization. Most received some type of medication and all attended occupational therapy and participated in ward clean-up chores. They were interviewed by their doctor and, in some cases, by a social worker and received medical attention 
for physical complaints. Otherwise, there was little staff intervention in their day to day activities.

Patients assigned to Experimental Group II received daily training in playing the normal role. E conducted daily sessions for members assigned to this group. Four to five patients were present at each session. They were presented with situations providing opportunities to play the normal role. The following procedures were employed:

I. Ss were presented with MMPI items not included in the Es and CI scales. They were asked to give the answers expected from a well-adjusted, normal person. E verbally reinforced a correct response and, in most cases, attempted to explain the healthy or normal aspects of the correct answer. Ten items were presented at each session.

2. Ss were shown a Rorschach Card and asked to determine which of two responses a normal, healthy person might choose as the best description of the inkblot (or portion of $i t)$. The choice was always between a F+ and F- response (as determined by Small, 1956). Five pairs of $W$ response choices and five of $D$ were used in each session. Some initial responses were used again during the latter sessions. E attempted to verbally reinforce and explain normal aspects of correct responses. 
3. Ss were presented with pairs of sentences. They were told that one of each pair might be expected from a well-adjusted person, the other from a sick person. The sentences were developed from the Rotter Incomplete Sentence BIank (ISB). E, with the aid of several graduate students in psychology, completed the phrases from the ISB, attempting to keep the sentence free of pathological content. With the aid of previously administered ISBs taken from the hospital files, E selected sentences which gave obvious expressions of unhealthy symptoms. Normal sentences were paired with abnormal ones for presentation to $\underline{S} s$. They were instructed to choose the sentence expected of a normal person. During latter sessions, $\underline{S}$ s were required to add to initial phrases presented by $E$ to make a sentence which sounded like it might well have been said by a normal person. Five pairs of sentences were used in each session.

4. Ss were asked to imagine a social situation which E described to them. The situations were devised as the study progressed. They included incidents common to ordinary experience, such as having friends stop by, going to the store, being stopped by a traffic policeman, etc. Ss were supplied with a choice between two types of responses to the depicted situation. One choice, 
as determined by $E$ with the aid of the same graduate students in psychology, was a normal, expected type of response; the other a deviant or abnormal response. After the tenth session Ss were required to propose situations drawn from their own experience and were requested to indicate a normal response to that situation. E allowed considerable discussion regarding the appropriate responses to the social situation. E took part in the discussion and attempted to indicate what he considered as healthy, normal behavior.

Patients in Experimental Group II were required to attend training session 5 days a week. Some missed occasional sessions because of other appointments or because they were receiving visitors. A few missed sessions because of illness. Three patients in the training group escaped from the hospital, but none for longer than 2 days. One patient had to be dropped from training because of a staff decision to administer electro-shock therapy. The mean number of sessions attended by Experimental Group II Sss was 18 .

The follow-up test on the day of staff conference allowed for a comparison of each $\underline{S}^{\prime} s$ initial and final role-playing scores. It also allowed for a comparison of trained and non-trained $\underline{S}$. Since the test was administered to the Control Group with standard instructions, it was possible to compare the differential effects of the two sets of instructions upon response. 
At the conclusion of this study, hospital records were searched. The staff diagnosis for each $\underline{S}$ was noted as well as the decision regarding release or continued hospitalization. 


\section{Results}

A simple analysis of variance was performed to determine whether the matching technique uitlized was effective in equating the three groups for age. The age range for Experimental Group I was 16 to 52 and the mean was 38.3 years, for Experimental Group II the range was 21 to 60 and the mean 34.9, and for the control Group the range was 17 to 49 and the mean 33.8. Table 2 shows the results of the simple analysis of variance and indicates that there were no significant differences regarding age.

Groups were also matched for years of formal education. The educational range for Experimental Group I was 3 to 16 years and the mean was 10.1 years, for Experimental Group II the range was 6 to 15 years and the mean was 10.8 years and for the control Group the range was 6 to 16 years and the mean was 9.5 years. Table 3 summarizes the results of a simple analysis of variance. performed on these data. No significant differences between the groups were found.

In addition to age and education, the groups were also equated for number of psychiatric admissions. Equating for length of previous hospitälizations would have been more desirable, but this information was not available from the hospital files due to incomplete records regarding private and out-of-state hospitalizations. The number of previous hospitalizations showed a 
TABLE 2

ANALYSIS OF VARIANCE FOR AGE DIFFERENCES

\begin{tabular}{lccc}
\hline & & & \\
\hline Source of Variance & df & Mean Square & $F$ \\
\hline Groups & 2 & 98.00 & .61 \\
\hline Within & 49 & 159.84 \\
\hline
\end{tabular}


TABLE 3

ANALYSIS OF VARIANCE FOR EDUCATIONAL DIFFERENCES

\begin{tabular}{lccc}
\hline & & & \\
\hline Source of Variance & df & Mean Square & F \\
\hline Groups & 2 & 7.00 & .94 \\
\hline Within & 49 & 7.45 & \\
\hline Total & 51 & & \\
\hline
\end{tabular}


markedly skewed distribution. Since $\underline{S}$ s were nearly evenly divided between one admission and two or more admissions, a non-parametric test was selected to determine whether group differences existed. The $\mathrm{x}^{2}$ Test showed that the matching technique maintained the number of first and multiple admissions in the three groups well within the area of chance distribution $\left(x^{2}=1.24, \mathrm{p} .>.50\right)$. The matching technique was successful in equating the three groups for age, education, and number of hospitalizations. Any correlations, therefore, between these variables and the roleplaying measures used should not be a factor in comparing the groups.

Es scores obtained from the initial tests, administered on the day following admission, were analyzed using a $3 \times 2$ factorial design to determine whether the three groups varied in their initial endorsement of Es items and whether psychotics and nonpsychotics distributed through the groups responded differentially. Staff conference diagnoses, which were determined independent of this study, indicated that the groups were composed of the following diagnoses: Experimental Group I: nine psychotic, nine non-psychotic; Experimental Group II: eight psychotic, nine nonpsychotic; and the Control Group: eight psychotic, nine nonpsychotic. This distribution is well within the area of chance effect, indicating that the groups do not differ diagnostically. The results of the analysis of initial Es scores, as indicated in Table 4, did not reveal a significant difference in the number 
TABLE 4

ANALYSIS OF VARIANCE OF INITIAL ES SCORES

\begin{tabular}{lccc}
\hline & df & Mean square & $F$ \\
\hline Diagnosis & 1 & 76.00 & 1.35 \\
\hline Groups (instructions) & 2 & 143.50 & $2.56^{*}$ \\
\hline Interaction & 2 & 11.50 & .21 \\
\hline Within Groups & 46 & 56.09 & \\
\hline
\end{tabular}

* Significant between .05 and .10 level 
of Es endorsements between psychotic and non-psychotic groups or among experimental and control groups. Likewise, the interaction was not significant.

The results of a $t$ Test, however, comparing the two experimental groups with the Control Group, revealed a significant difference $(t=1.88, p<.05)$. Normalcy instructions, therefore, caused significantly higher endorsement of Es items. Table 5 shows the groups' mean Es and CI endorsements and their standard deviations.

A $3 \times 2$ factorial analysis was employed to determine whether the three groups varied in their initial endorsement of $C I$ items and whether psychotics distributed throughout the groups endorsed significantly more items than non-psychotics. Table 6 shows that the groups did not vary beyond chance level on the CI measure, nor did psychotics and non-psychotics show a significant difference. There was no significant interaction. A $t$ Test showed a significant difference between the combined experimental groups and the Control Group $(t=2.30, p<.05)$. Normalcy instructions, therefore, caused significantly lower endorsement of CI items.

The ability to role-play normalcy, as measured by endorsement of Es and CI items with normalcy instructions, was compared with age, education, and number of hospitalizations. Age showed only small insignificant correlations with Es $(r=.08)$ and CI $(r=.09)$ endorsements, indicating that the ability to role-play as determined by the measures used in this study was not dependent upon age. 
TABLE 5

MEAN ES AND CI ENDORSEMENTS

\begin{tabular}{|c|c|c|c|c|c|}
\hline & & ES & & CI & \\
\hline Subjects & $\mathrm{N}$ & Mean & $\mathrm{SD}$ & Mean & SD \\
\hline Experimental Group I & 18 & 39.6 & 6.4 & 5.1 & 5.5 \\
\hline ExperimentaI Group II & 17 & 37.7 & 6.7 & 4.8 & 3.4 \\
\hline Control Group & 17 & 35.5 & 9.3 & 8.6 & 5.7 \\
\hline
\end{tabular}


TABLE 6

ANALYSIS OF VARIANCE OF INITIAL CI SCORES

\begin{tabular}{lccc}
\hline & df & Mean Square & $F$ \\
\hline Source of Variance & 1 & 43.20 & 1.75 \\
\hline Groups (instructions) & 2 & 76.25 & .33 \\
\hline Interaction & 2 & 24.45 & \\
\hline Within Groups & 26 & 24.70 & \\
\hline
\end{tabular}

* Significant between .05 and .10 level 
Years of formal education, when compared with role-playing ability measured by the Es scale indicated a significant correlation $(r=.65, p<.01)$. However, when education was correlated with the ability to role-play, measured by the CI scale, a small insignificant correlation resulted $(r=-.15)$.

Since the distribution of the number of hospitalizations did not lend itself to the correlational technique used above, $t$ Tests were used to compare the endorsements of Es and CI items of first admissions with the endorsements of $\underline{S}$ with multiple hospital admissions. First admissions endorsed more Es items, but this difference was not significant ( $t=.81, p>.10)$. S with multiple admissions endorsed more CI items but, once again the difference was not significant $(t=1.03, p>.10)$. One of the primary concerns of the study and a direct test of the first hypothesis were the changes between initial and final endorsement of Es and CI items. The distribution of the changes included several aberrant scores which added considerably to the total variance. Parametric tests were employed to analyze the group changes, but did not reflect differences at an acceptable level of confidence. A comparison of the three groups on improvement in Es endorsement (endorsing more Es items correctIy) indicated a F of 1.50', significant at greater than the .25 level, but beyond the acceptable level of confidence. $t$ Tests were used to compare the Training Group with Experimental Group I and the Control Group. The results $(t=1.76$ and $t=1.75)$ were both 
significant at the .10 level of confidence. An examination of the three groups'improvement in CI endorsement (endorsing less CI items) reflected even more aberrant scores than on the Es measure and a parametric analysis was even less appropriate. A F of .83 indicated no significant group differences. $t$ Test comparing the Training Group with Experimental Group I and the Control Group reflected ts of 1.25 and 1.30 which both fall short of the . 10 level of significance.

In order to eliminate the effect of aberrant scores, nonparametric tests were used to investigate changes between initial and final tests. The Kruskal-Wallis One Way Analysis of Variance indicated that the changes among groups on the Es scale between test and retest varied just below the .05 level of confidence $(H=5.80 ; .05<p<.10)$. The Mann-Whitney U Test showed no significant difference between the amount of change reflected by Experimental Group I and that of the Control Group $(U=138.5$, $\mathrm{P}>.10)$. The Training Group was compared with Experimental Group I and the Control Group individually by means of means of the Mann-Whitney $U$ Test. The results $(U=92.0$ and $U=83.5)$ were both significant at the .05 level, indicating that trained Ss showed more improvement than non-trained $\underline{S} s$ in the final endorsement of Es items. The median ranks of the groups regarding Es scale changes were: Experimental Group I: 15, Experimental Group II: 34, and Control Group: 20. Table 7 shows the groups' raw 


\section{TABLE 7}

MEAN CHANGES BETWEEN INITIAL AND FINAL ES AND CI ENDORSEMENTS

\begin{tabular}{|c|c|c|c|c|c|}
\hline \multirow[b]{2}{*}{ Subjects } & \multirow[b]{2}{*}{$\mathrm{N}$} & \multicolumn{2}{|c|}{ ES } & \multicolumn{2}{|c|}{$C I$} \\
\hline & & Mean & SD & Mean & SD \\
\hline Experimental Group I & 18 & 3.05 & 7.74 & 1.45 & 4.58 \\
\hline Experimental Group II & 17 & 5.77 & 3.69 & 2.82 & 2.98 \\
\hline Control Group & 17 & 1.59 & 7.71 & 1.71 & 3.45 \\
\hline
\end{tabular}


score changes. The group changes were all in the direction of improvement and represented increases of $8 \%, 15 \%$, and $5 \%$ respectively over initial Es scores.

The same non-parametric method was used to investigate the changes between test and retest on the CI scale. The Kruskal-Wallis One Way Analysis of Variance, however, indicated that the group changes did not vary at a significant level ( $H=1.01, P>$ .10) The median ranks of the groups regarding CI scale changes were: Experimental Group I: 24, Experimental Group II: 31, and Control Group: 24. Table 7 above shows the group changes in terms of raw scores. The $C I$ changes were all in the direction of improvement and represented increases of $29 \%, 59 \%$, and $20 \%$ respectively over the groups' initial scores.

Unrelated to the hypotheses being tested, but of considerable interest, were possible relationships between the ability to improve in simulating normalcy and factors such as age, education, and number of hospitalizations. As pointed out above, no correlation was found between the ability to role-play normalcy and age. A positive correlation, however, of $.70(\mathrm{p}<.01)$ was found between improvement in role-playing normalcy on the Es scale and age. Only $\underline{S} s$ in Experimental Group II were used in computing this correlation. When the same comparison was made, substituting role-playing normalcy on the CI scale in place of the Es scale, no significant correlation was found $(r=.38, p>.05)$. Rank 
order correlations were used.

Education was similarly correlated with improvement in the ability to simulate normalcy after training in role-playing. When the Es scale was used as a measure of improvement, the correlation was .55 significant at the .05 level of confidence. When the CI scale was used, an insignificant correlation of .35 was found.

Patients who had not been previously admitted to a psychiatric hospital were compared with those who had multiple psychiatric admissions on improvement shown in simulating normalcy on the Es and CI scales after training. If the retest of role-playing ability indicated an improved score (increased Es endorsement; fewer CI endorsements) improvement occurred; if the retest showed the same or a poorer score than on the initial test, no improvement occurred. The Fisher Exact Probability Test indicated that the direction of change in the ability to simulate normalcy was not significantly different between first and multiple admissions on either the Es or CI measures $(p=.53$ and $p=.28)$.

A final series of tests was used to analyze the relationship between improvement in the ability to simulate normalcy and release from the hospital. The Mann-Whitney U Test was used to compare those released from the hospital and those detained on improvement in role-playing normalcy on the Es scale. The results $(z=2.50, p<.01)$ indicated that those released were significantly more likely to show improvement than those detained. 
When the CI scale was used as the measure of improvement, a similar finding resulted $(z=5.86, p<.01)$. The median rank of released patients on improvement on the Es scale was 21 , that of detained patients was 11 . On the CI scale, the median rank of released patients was 22 , that of detained was 8 .

Experimental Group I and II improvers were compared on the likelihood of being released. The Fisher Test showed that trained Ss who improved were more likely to be released from the hospital than untrained $\underline{\text { Ss }}$ who also showed improvement in role-playing ability as measured by the Es scale $(p=.05)$. However, on the CI scale, this comparison does not reach significance $(p=.12)$. The Es finding suggests that the reason for more releases among trained Ss may lie in some effect of the training sessions in addition to improvement in role-playing ability, since trained improvers did not show more improvement than non-trained improvers $(z=1.32, p>.05)$. The median rank of trained improvers on the Es scale improvement was 12 , that of untrained improvers 15 $(N=26)$.

A final test was performed to determine whether release rate among the three groups varied beyond a chance level. Table 8 shows that $\underline{S}$ s wo received training in simulating normalcy were released from the hospital after the 30 day observation period

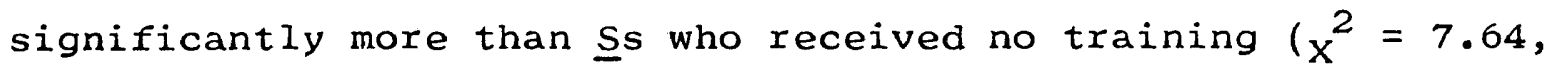
$\mathrm{p}<.05)$ 
TABLE 8

$x^{2}$ TEST FOR DIFFERENCES IN RELEASE RATE AMONG THE THREE GROUPS

\begin{tabular}{lccc}
\hline & & & \\
\hline Subjects & Released & Detained & Total \\
\hline Experimental Group I & II & 7 & 18 \\
\hline Experimental Group II & 16 & 1 & 17 \\
\hline Control Group & 9 & 8 & 17 \\
\hline Total & 36 & 15 & 52 \\
\hline
\end{tabular}




\section{Discussion}

Hypothesis 1. The first hypothesis predicted that a retest of role-playing ability administered after a period of hospitalization would demonstrate a diminished ability to play the normal role. Experimental Group I was designed to test this hypothesis.

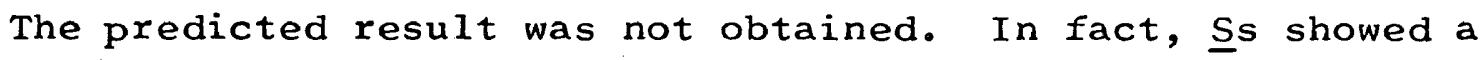
mean improvement, though not a significant one, in both the measures of role-playing ability employed here.

Rejection of the first hypothesis might be attributed to several factors superseding the effects of the labeling process. Some patients may be motivated by the unpleasantness of the labeling process to make an increased effort to play normal roles. Hospitalization itself might be offensive enough to encourage some patients to make an attempt at appearing normal and no longer in need of treatment. Exposure to other mental patients may underscore the desirability of normal roles. It is a generally well known fact that patients prompt one another in techniques of impressing the staff to increase chances of discharge. Because hospitalization may be less stressful than a patient's previous situation, improvement may occur. And finally, the hospital may have theraputic effects upon the patient.

Despite factors which would encourage improvement in roleplaying skills, eight of 18 patients in Experimental Group I 
showed deterioration in their ability to simulate normalcy. An interesting hypothesis for further research might be an investigation of the predictive value of decreased skill in role-playing as an index of ultimate committment to the deviant role as measured by continued or subsequent hospitalization.

Test-retest reliability plays an important role in measures such as the ones employed here. Pauker (1966) has argued for the stability of the MMPI, but a more consistent consensus sees marked changes upon retest due to alterations in mood, motivation, and stress. It is difficult to partial out the reliability of the tests used here from the effects of hospitalization. The present study contained a measure of the combination of these factors. Standard MMPI instructions were given to control $\underline{S}$ s when administered the Es and CI scales. The test-retest correlations (interval $=30$ days) were .63 and .91 respectively. The contribution of reliability factors alone to the findings of this study remains largely undetermined and inseparable from the effects of hospitalization. In addition, the sensitivity of the measures to role-playing ability is an assumption based upon only a few previous studies. There is no strong evidence that they are capable of a valid estimate of the ability to simulate normalcy. The role-playing model, with aid from dissonance, learning, and conformity theories seems to suggest the first hypothesis, but mental patients are probably subjected to further pressures than 
the ones dealt with by these theories. An experimentai design more sensitive to the complexity of the situation confronting the newly-labeled and hospitalized deviate might prove more adequate in adapting and testing the first hypothesis. The measures employed here will be discussed at more length later. However, at this point, it can be concluded that, if the same measured were to be used again, more would have to be known concerning their reliability and sensitivity to improvement in role-playing ability.

Hypothesis 2 . The second hypothesis predicted that patients released from the hospital after the 30 day observation period would be those who showed improvement in their ability to play the normal role. When released patients were compared with those detained for further treatment, it was found that the first group was able to simulate normalcy more effectively than the second according to both measures taken.

Hypothesis 3 . The third hypothesis predicted that trained Ss would show improvement in their ability to simulate normalcy and be released from the hospital at a greater rate than nontrained $\underline{s}$. The first prediction was substantiated on the Es measure, but not on the CI measure, although the change on the latter scale was in the expected direction. The prediction regarding release rates was substantiated, but a causal relationship with improvement in role-playing ability was not established. 
Improvement in role-playing ability was called into question as a reason for the increased release rate among trained $\underline{S}$ by

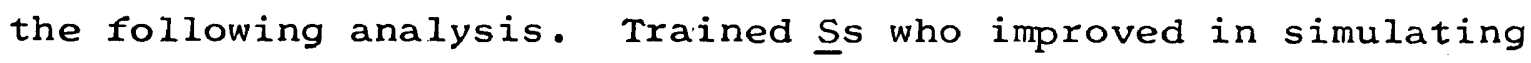
normalcy were compared with untrained $\underline{S} s$ who showed improvement. No significant difference was revealed between the two groups' improvement. The same $\underline{S} s$ were compared on number of releases and the results showed that the trained $\underline{S}$ s were released significantly more often. This finding suggests that trained $\underline{S}$ may have gained release for reasons other than improved ability to

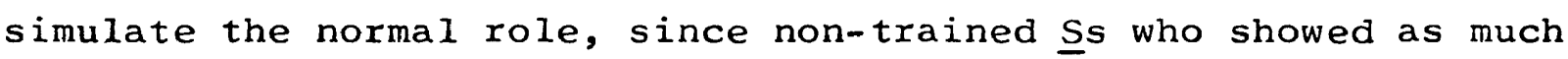
improvement did not reflect as high a release rate. Some of the factors possibly contributing to the higher release rate among trained improvers will be discussed later.

Increased ability in simulating normalcy can only be ruled out as an explanation for additional releases, if it is assumed that representative measures of role-playing were employed in this study. If trained $\underline{S} s$ did, in fact, improve in their ability to simulate normalcy in ways that non-trained improvers did not, increased role-playing ability may have effected the higher release rate. Improvement, undetected by the Es and CI measures may have been present as a result of training and capable of bringing about a favorable decision regarding release at staff conference. It is difficult to endorse such an interpretation without additional information concerning the measures used. It is an interesting 
explanation, however, and could be evaluated by further research. Measures. In discussing the findings, there have been several occasions where either the reliability or validity of the Es and CI measures have been questioned. These two features were assumptions of the experimental design. There was no conclusive evidence that these assumptions are well-founded ones. Some estimate of reliability was available from previous MMPI studies and validity was largely assumed on the basis of a few experiments which employed the MMPI or portions of it as a role-playing vehicle (i.e.̈. Grayson and Olinger, 1957; Haas and Cabin, 1966). Furthermore, patients' ability to simulate normalcy in a test situation may differ from the degree to which their extra-test behavior deviates from normalcy. A person might know what behavior is normal and expected and be able to demonstrate this on a test, but choose not to regulate his own actions accordingly. The test situation, then, might not have provided true estimates of a patient's committment to the deviant role.

In several instances, the two measures employed in this study showed differential results in their estimation of role-playing ability. The Es scale generally appeared to be the more sensitive of the two instruments. Grayson and olinger (1957) found that patients are more successful in simulating normalcy on the Es scale than on any of the clinical scales of the MMPI. This finding is in agreement with the results of the present study in that more 
discriminations were possible when Es was used as a measure rather than $\mathrm{CI}$.

In this study, CI endorsement was relatively low in terms of the total number of CI items. The Control Group which endorsed items to express their real feelings showed only a mean endorsement of 8.6 items on the initial test and less on the retest. The experimental groups endorsed less than control $\underline{S}$ s on both tests. The content of the CI scale is evidently so pathological that patients were able to admit to or interpret as normal only relatively few items. Psychotic patients did not endorse significantly more CI items than did non-psychotics. Despite their disorientation and confusion, psychotics were able to recognize the pathology of CI items and refrain from endorsing them. This finding suggests that the scale was inappropriate for this study. One more sensitive to the differences between psychotic and non-psychotic Ss would have been more useful.

Though standardization would be a considerable project, imagined social situations with prearranged response choices similar to those used as a technique for role-training here - might be employed as a useful measure of role-playing ability. A series of social situations would provide an opportunity for $\underline{S}$ to demonstrate his ability to play the normal role. Such a measure might be more successful at discriminating diagnostic categories and the effects of training. 
Training. The significantly increased release rate demonstrated by trained $\underline{S} s$ over that of non-trained $\underline{S} s$ indicates that training sessions may have been in some way related to favorable staff decisions regarding the termination of hospital treatment. It should be noted that those persons involved in making the staff decision regarding release or detention were unaware of which patients were receiving training in role-playing. In fact, most remained completely unaware of the fact that a study was being conducted. It appears, therefore, that there was no bias concerning trained $\underline{S}$ s on the part of staff members involved in making release decisions.

The training sessions lasted at least. 20 minutes, but rarely more than a half-hour. While this is a relatively small portion of the patient's day, it did appear to be a significant part. In terms of structure and directiveness, training sessions probably rated consistently higher than most other staff-patient contacts. A typical day for patients on the observation ward consists of long periods of free time, occasionally punctuated by hurried trips to the cafeteria, occupational therapy shops, and recreation building. Contact with the staff is generally with the lower echelons - attendants and aides - and is often limited to disciplinary matters. Śs who attended training sessions, however, usually developed a reasonably close relationship with $\mathrm{E}$ whom they perceived as a psychologist or doctor. This daily confrontation 
with an interested staff member armed with a positive treatment plan probably had a considerable impact upon trained $\underline{S}$.

Despite the intention of utilizing daily training sessions for the purpose of increasing role-playing skills, there were other inseparable aspects which might have contributed greatly or even have been entirely responsible for the high release rate of trained Ss. In light of the differential treatment Group II received, the high release rate might be interpreted as an instance of the Hawthorne effect. It is possible that the training group developed an "esprit de corps" which provided increased motivation to resist society's labeling process and to imitate E. E's observations suggested that. $\underline{S}$ in the training group often formed friendships and were more likely to be seen conversing with one another than with non-trained $\underline{S} s$. This impression was confirmed by several ward attendants. Perhaps, selection for participation in the training sessions and acceptance by the group was sufficient to provide the incentive and effort necessary to gain release from the hospital.

Training sessions were generally attended by four or five $\underline{S}$. Although there was a consistent attempt to restrict the sessions to an objective consideration of normal behavior and opportunities to role-play such behavior, it was impossible to restrain $\underline{S}$ from referring the matter being discussed to problem areas of their own behavior. There were numerous occasions when $\underline{S}$ s indicated to the group that the current consideration had personal applications. 
Discussion often followed and, until E halted it, the situation was very similar to that effected by group therapy. Whether or not these incidents encouraged the beneficial changes sometimes afforded to participants in group therapy is largely a matter of speculation, but could be resolved by further research. In the event that there were theraputic benefits gained by the support of the group and the realization that problems are common to all, trained $\underline{S}$ were more likely to rally and gain release at the end of the observation period.

At Eastern State Hospital, staff conferences regarding release vs. continued treatment are conducted weekly. An attempt is made to evaluate patients' physical, social, and psychiatric condition. Reports are presented by doctors, social workers, psychologists, and ward nurses. The patient under consideration is brought into the room where these people are gathered and is interviewed in the presence of all by a staff psychiatrist. Following the interview, the staff comes to a decision on the basis of the reports and interview regarding the termination of hospitalization. Often the interview is the key factor in the decision. If a patient appears fairly intact according to the various reports, but conducts himself in a confused and disoriented fashion during the staff interview, he is likely to be detained at the hospital. On the other hand, a questionable impression created by the reports, followed by a good showing during the interview will influence 
the decision in the direction of release.

The daily training sessions were held in a room similar to the one in which staff conferences were conducted. Furthermore, several other people were always present, one of whom was a staff member who required responses from the patients. These conditions somewhat approximated those of staff conference. Repeated exposure to this situation through daily sessions probably reduced the level of stress normally accompanying the staff conference interview. Trained patients, as a result, might have been able to function in a less threatened manner and may have created a more favorable impression during the staff conference interview, thereby increasing their chances of release.

Finally, the high release rate in the training group might actually be attributed to improvement in role-playing abilit $\hat{y}$. The measures of role-playing used in this study may have been insensitive to increases in role-playing ability gained by trained Ss. Trained improvers were not significantly different from untrained improvers according to the Es and CI measures, but trained improvers may have become more facile at role-playing normalcy in ways untapped by the measures. Such improvement, then, may have been responsible for the higher release rate among trained $\underline{S}$.

The Social Model. The present study used a fresh approach to the study of mental illness. There are few theorists who have come to visualize mental disorder in terms of its being an effect 
of societal reaction. Those who are using this approach may be making an important contribution toward a more complete understanding of mental illness. Scheff (1966) has pointed out that the social model does not present itself as a total explanation of mental illness, but rather as an essential factor to be reckoned with in any complete examination of the etiology of mental disorder. The importance of societal reaction in the formation of mental illness remains largely undetermined, but Becker (1963) and Scheff (1966) have suggested that its role might ultimately be proven surprisingly important. 
APPENDIX

The appendix contains the combined Es and CI scales in the same form presented to Ss participating in this study. 
Name :

Sex :

Age :

Education:

Occupation:

Marital Status:

Admission:

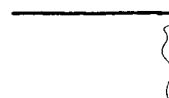

1. I have a good appetite.

2. I have diarrhea once a month or more.

3. My sex life is satisfactory.

4. At times I have fits of laughing and crying that

I cannot control.

5. Evil spirits possess me at times.

6. I find it hard to keep my mind on a task or job.

7. I have had very peculiar and strange experiences.

8. I have a cough most of the time.

9. I seldom worry about my health.

10. I have never been in trouble because of my sex behavior.

11. My sleep is fitful and disturbed.

12. Much of the time my head seems to hurt all over.

$\stackrel{T}{\mathrm{~T}}(\mathrm{~F})$

$(\quad) \quad(\quad)$

( ) ( )

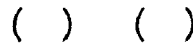

( ) ( )

( ) ( )

()()

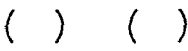

( ) ( )

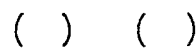

()()

( ) ( )

13. When I am with people I am bothered by hearing very queer things.

14. I am in just as good physical health as most of my friends.

15. Everything is turning out just like the prophets of the Bible said it would.

16. Parts of my body often have feelings like burning, tingling, crawling, or like "going to sleep." 
17. I see things or animals or people around me that others do not see.

18. I am very stongly attracted by members of my own sex.

19. I have often wished I were a girl. (or if you are a girl) I have never been sorry that I am a girl.

20. I am easily downed in an argument.

21. Sometimes I am strongly attracted by the personal articles of others such as shoes, gloves, etc., so that. I want to handle or steal them though I have no use for them.

22. I do many things which I regret afterwards (I regret things more or more often than others seem to.( ) ( )

23. I go to church almost every week.

24. I have met problems so full of possibilities that I have been unable to make up my mind about them.

25. Some people are so bossy that I feel like doing the opposite of what they request, even though I know they are right.

26. Often I feel as if there were a tight band about my head.

27. I believe I am being plotted against.

28. I believe I am being followed.

29. I like collecting flowers or growing house plants.

30. I have never indulged in any unusual sex practices.

31. Sometimes I feel as if I must injure either myself or someone else.

32. I like to cook.

33. I have the wanderlust and am never happy unless I am roaming or traveling about.

34. Someone has been trying to poison me.

35. During the past few years I have been well most of the time. 
36. I have had periods in which I carried on activities without knowing later what I had been doing.

37. There is something wrong with my mind.

38. I have never had a fainting spell.

39. I am worried about sex matters.

40. When I get bored I like to stir up some excitement.

41. I am afraid of losing my mind.

42. I commonly hear voices without knowing where they come from.

43. My hands have not become clumsy or awkward.

44. I feel weak all over much of the time.

45. I have had no difficulty in keeping my balance in walking.

46. There are persons who are trying to steal my thoughts and ideas.

47. I believe I am a condemned person.

48. At times it has been impossible for me to keep from stealing or shoplifting something.

49. I like to flirt.

50. I believe my sins are unpardonable.

51. I have used alcohol excessively.

52. I frequently find myself worring about something.

53. I like science.

54. I like to talk about sex.

55. I get mad easily and then get over it soon.

56. I brood a great deal.

57. I dream frequently about things that are best kept. to myself.
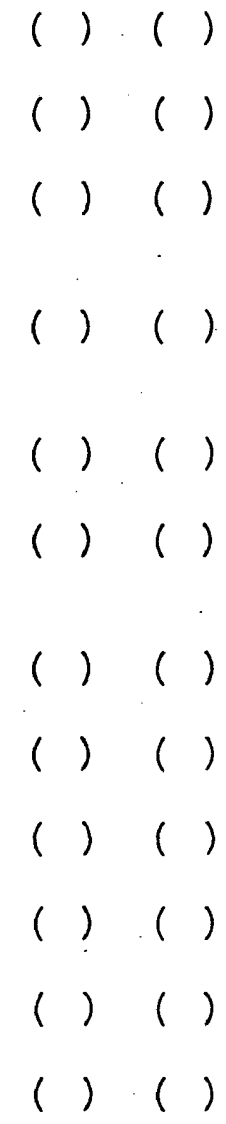

( ) ( )

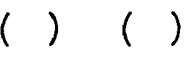

()$(1)$ 
58. My way of doing things is apt to be misunderstood by others.

59. I have had blank spells in which my activities were interrupted and I did not know what was going on around me.

60. I can be friendly with people who do things which I consider wrong.

61. When I leave home I do not worry about whether the door is locked and the windows closed.

62. Someone has control over my mind.

63. At one or more times in my life I felt that someone was making me do things by hypnotizing me.

64. Someone has been trying to influence my mind.

65. Peculiar odors come to me at times.

66. I feel anxiety about something or someone almost all the time.

67. Most of the time I wish I were dead.

68. At times I hear so well it bothers me.

69. Often I cross the street in order not to meet someone I see.

70. I often feel as if things were not real:

71. I have strange and peculiar thoughts.

72. I hear strange things when I am alone.

73. I am afraid of using a knife or anything very sharp or pointed.

74. Sometimes I enjoy hurting persons I love.

75. Sometimes some unimportant thought will run through my mind and bother me for days.

76. I am not afraid of fire.

77. I do not like to see women smoke.

78. When someone says silly or ignorant things about something I know about, I try to set him right. 
79. I feel unable to tell anyone all about myself.

80. My plans have frequently seemed so full of difficulties that I have had to give them up.

81. I would certainly enjoy beating a crook at his own game.

82. I have had some very unusual religious experiences.

83. One or more members of my family is very nervous.

84. I am attracted by members of the opposite sex.

85. The man who had most to do with me when $I$ was a child (such as my father, stepfather, etc.) was very strict with me.

86. Christ performed miracles such as changing water into wine.

87. I pray several times every week.

88. I feel sympathetic towards people who tend to hang on to their griefs and troubles.

89. I am afraid of finding myself in a closet or small closed place.

90. Dirt frightens or disgusts me.

91. I think Lincoln was greater than Washington.

92. In my home we have always had the ordinary necessities (such as enough food, clothing,etc.).

93. I am made nervous by certain animals.

94. My skin seems to be unusually sensitive to touch.

95. I feel lazy a good deal of the time.

96. I never attend a sexy show if I can avoid it.

97. If I were an artist I would like to draw children.

98. I sometimes feel that I am about to go to pieces.

99. I have often been frightened in the middle of the night.

100. I very much like horseback riding.

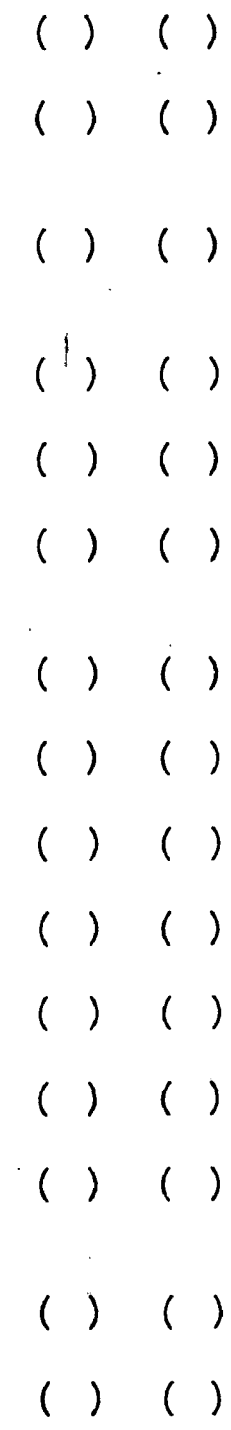




\section{Bibliography}

Adler, A. The practice and theory of individual psychology. New York: Harcourt, 1927 .

Angyal, A. Disturbances in thinking in schizophrenia. In J. S. Kasanin (Ed.). Language and thought in schizophrenia. Los Angeles: University of California Press, 1946.

Asch, S. E. Studies of independence and conformity: A minority of one against a unanimous majority. Psychological Monographs, 1956, 70, No. 9 (whole No. 416. ).

Aylion, T. Intensive treatment of psychotic behaviour by stimulus satiation and food reinforcement. Behaviour Research and. Therapy, 1963, 1, 53-61

Bandura, A., and Walters, R. H. Social learning and personality development. New York: Holt, Rinehart and Winston, 1963.

Barron, F. An Ego-strength scale which predicts response to psychotherapy. Journal of Consulting Psychology, 1953, $17,327-333$.

Becker, H. S. Outsiders. New York; McGraw Hill, 1951.

Bleuler, E. Dementia praecox. New York; International Universities Press, 1950.

Book, J. A. A genetic and neuropsychiatric investigation of a North Swedish population with special regard to schizophrenia and mental deficiency. Acta Genetica, 1953, 4, 1-100, $133,139,341-414$.

Chambers, J. L. Trait judgment of photography by neuropsychiatric patients. Journal of Clinical Psychology, 1957, 13, 393-396.

Clarke, C. T. Changes in self-concept as a function of dissonant Ir playing. Dissertation Abstracts, 1965, 26, (3), 1771.

Cohen, A. K. The sociology of the deviant act; anomic theory and beyond. American Sociological Review, 1965, 30, 5-14.

Crammer, J. L. Rapid weight changes in mental patients. The Lancet, $1957,259-262$.

Davidson, A. P. A public opinion game. Public Opinion. Quarterly, 1961, 25, 210-220. 
Eysenck, H. J. Learning theory and behavior therapy. Journal of Mental Science, 1959, 105, 61-75.

Festinger, L. A Theory of cognitive dissonance. Stanford: Stanford University Press, 1957.

Freud, S. The Ego and the id. London: Hogarth Press, 1947.

Friedman, I. Phenomenal, ideal and real projections of self. Journal of Abnormal and Social Psychology, 1955, 51, 611-

Goffman, E. Asylums. New York: Doubleday, 1961.

Goldstein, K. The significance of psychological research in schizophrenia, Journal of Nervous and Mental Disease, $1943,97,261-279$.

Grayson, H. M., and Olinger, L. B. Simulation of "normalcy" by patients on the MMPI. Journal of Consulting Psychology, $1957, \underline{21}, 73-77$.

Grayson, H. M. A psychological admissions testing program and manual. Los Angeles: Veterans Administration Center, Neuropsychiatric Hospita I, 1951.

Haas, K., and Seymour, H. C. Role-playing ability and clinical progress in a psychiatric state hospital. Journal of General Psychology, 1966, 75, 161-165.

Heath, R. G. A biochemical hypothesis on the etiology of schizophrenia. In D. D. Jackson (Ed.), The etiology of schizophrenia. New York: Basic Books, $1 \overline{960}, \frac{\mathrm{Pp} 146-156 .}{15}$

Hillson, J. S., and Worshal, P. Self-concepts and defensive behavior in the maladjusted. Journal of Consulting Psychology, 1957, 21, 83.88.

Hollingshead, A. B., and Redlich, F. C. Social class and mental illness. New York: Wiley, 1958.

Kitsuse, J. Societal reaction to deviance: problems of theory and method, Social Problems, $1962, \underline{9}, 247-256$.

Klein, G. S. The personal world through perception. In R. R. Blake and C. V. Ramsey (Eds.), Perception. New York: Ronald, 1951, Pp 328-355. 
Lazarus, A. A. The treatment of chronic frigidity by systematic desensitization. Journal of Nervous and Mental Disease, $1963, \underline{136}, 272-278$.

Lemert, E. M. Social pathology, New York: McGraw - Hill, 1951.

Leveen, L., and Priver, D. Significance of role-playing in the aged person. Geriatrics, 1963, 18, 57-63.

Mahrer, A. R. Psychological symptoms as a function of psychiatric hospitalization. Psychological Reports, 1963, 13, 266.

Mann, J. H., and Borgatta, E. F. Personality and behavior correlates of changes produced by role-playing experience Psychological Reports, 1959, 5, 505-526.

Merton, R. K. Social problems and sociological theory. In R. K. Merton and R. A. Nisbet (Eds.), Contemporary social problems. New York: Harcourt, Bruce, and World, 1961 , Pp 697-737.

Moreno, J. L. Role theory and the emergence of the self. Group Psychotherapy, 1962, 15, 114-117.

Myers, J. K., and Roberts, B. H. Family and class dynamics in mental illness. New York: Wiley, $1 \overline{959}$.

Newcomb, T. M., Turner, R. H., and Converse, P. E. Social psychology: The study of human interaction. New York: Holt, Rinehart, and winston, 1965. Pp. 391-409.

Pauker, J. D. Stability of MMPI profiles of female psychiatric inpatients. Journal of Clinical Psychology, 1966, 22, 209-212.

Rogers, L. R. Client-centered therapy, New York: HoughtonMifflin, 1951.

Rogers, A. H. The self-concept in paranoid schizophrenia. Journal of Clinical Psychology, 1958, 14, 365-366.

Sarbin, T. R. Studies in behavior pathology. New York: Holt Rinehart and Winston, 1944 .

Sargent, H. Projective methods; their origins, theory, and application in personality research. Psychological Bulletin, $1945, \underline{42}, 257-293$.

Scheff, T. J. Being mentally ill. Chicago: Aldine, 1966. 
Schwartz, M., Fearn, G. F. N., and Stryker, S. A note on selfconception and the emotionally disturbed role. Sociometry, $1966,29,300-308$.

Senf, R., Hutson, P., and Cohne, B. The use of comic cartoons for the study of social comprehension in schizophrenial. American Journal of Psychiatry, 1956, 113, 45-51.

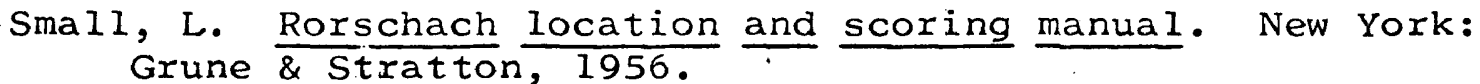

Stanton, A. H., and Schwartz, M. S. The mental hospital. New York: Basic Books, 1954 .

Stevens, S. S. Mathematics, measurement and psychophysics. In S. S. Stevens (Ed.), Handbook of experimental psychology. New York: Wiley, 1951, Pp 28-33.

Sullivan, H. S. The interpersonal theory of psychiatry. New York: Norton, 1953.

Szasz, T. S. The myth of mental iliness. New York: HoeberHarper, $1 \overline{961}$.

Willens, J. G. Training role behavior in schizophrenics. Dissertation Abstracts, 1965, 26, (6), 3492-3493.

Witkin, H. A. Personality through perception. New York: Harper, 1954.

Wolpe, J. Psychotherapy by reciprocal inhibition. Stanford: Stanford University Press, 1958.

Wolpe, J. The systematic desensitization treatment of neurosis. Journal of Nervous and Mental Disease, 1961, 132, 189-203. 
VITA

Frank A. Chesno

Born in Baltimore, Maryland, October 28, 1943. B.S. in Psychology, Loyola College of Baltimore, June 1966. Candidate for the Degree of Master of Arts in Psychology, The College of William and Mary, September, 1966 - June, 1968. 